\title{
OS PLANOS DE ELABORAÇÃO DE O CAPITAL E O PROBLEMA DA CRISE CAPITALISTA EM MARX
}

\author{
LOS PLANES DE ELABORACIÓN DE EL CAPITAL Y EL PROBLEMA DE LA CRISIS \\ CAPITALISTA EN MARX
}

\section{THE ELABORATION PLANS OF CAPITAL AND THE PROBLEM OF THE CAPITALIST CRISIS IN MARX}

DOI: http://dx.doi.org/10.9771/gmed.v11i3.34955

\author{
Jadir Antunes ${ }^{1}$
}

Resumo: Nosso artigo pretende apresentar uma explicação do problema da crise capitalista em Marx a partir da leitura de $O$ Capital que combine ao mesmo tempo sua dimensão econômica e sua dimensão política, mostrando a importância desta combinação dialética ao longo do conjunto de O Capital.

Palavras-chave: Karl Marx; O Capital; crise; economia; política.

Resumen: Nuestro artículo pretende presentar una explicación del problema de la crisis capitalista en Marx a partir de la lectura de El Capital, que combina al mismo tiempo su dimensión económica y su dimensión política, mostrando la importancia de esta combinación dialéctica en todo el conjunto de El Capital.

Palabras-clave: Karl Marx; El Capital; crisis; economía; política

Abstract: Our article intends to present an explanation of the capitalist crisis's problem in Marx's Capital which combines at the same time its economic dimension and its political dimension, showing the importance of this dialectical combination throughout the set of Capital.

Key-words: Karl Marx; Capital; crisis; economy; politics.

\section{Apresentação do problema}

Nosso artigo pretende apresentar uma explicação do problema da crise capitalista em Marx a partir da leitura de $O$ Capital que combine ao mesmo tempo sua dimensão econômica e sua dimensão política²

De maneira geral, a bibliografia marxista sobre o problema da crise separa estas duas dimensões, priorizando a investigação das causas econômicas da crise e a análise das tendências futuras do desenvolvimento econômico capitalista. As diversas teorias procuram demonstrar que há uma causa central para a explicação das crises na concepção de Marx. Estas teorias procuram compreender o movimento cíclico das crises, e assim, somente seu ordenamento empírico e causal.

De modo geral, os diversos comentadores da crise buscaram encontrar nos textos de O Capital uma passagem determinada que mostrasse a causa principal que impulsionaria a produção capitalista a entrar regularmente em choque consigo mesma. Entre as diversas causas estas teorias sublinham: a anarquia do mercado, a superprodução de mercadorias, o subconsumo das massas, a baixa tendencial da taxa de lucro, 
a desproporção intersetorial entre os departamentos I e II da produção, a renovação periódica do capital fixo e a superacumulação de capital.

Assim, os diversos comentadores da crise capitalista, tais como Rosa Luxemburg, Henryk Grosman, Rudolf Hilferding, Paul Sweezy e Ernest Mandel ${ }^{3}$, procuraram encontrar nos textos de O Capital uma passagem determinada que demonstrasse a causa principal da crise ${ }^{4}$.

Nessa busca, tais autores deram ênfase a três fragmentos de texto distribuídos entre os três livros de O Capital, e mesmo de Teorias sobre a Mais-valia. Os partidários da desproporção entre os diferentes departamentos da produção e da anarquia do mercado como causas centrais da crise, por exemplo, escolheram a Seção II do Livro II de O Capital, onde Marx analisa o problema da reprodução social do capital global e as possibilidades de crise que surgem de uma reprodução desproporcional. Os partidários da lei da queda tendencial da taxa de lucro como a causa central escolheram a Seção III do Livro III de $O$ Capital, onde Marx analisa esta questão. Os partidários da superprodução, por sua vez, se apoiaram sobre o Capítulo XVII de Teorias sobre a Mais-valia e sobre a crítica de Marx ao equilíbrio de mercado defendido por David Ricardo.

Estes autores, conduzidos pelo uso da noção não dialética de causa, se desviaram do centro do problema, tentando descobrir, afinal, qual seria a verdadeira causa da crise e em qual passagem de O Capital Marx teria exposto melhor ou de forma mais completa a sua concepção principal de crise. Mesmo aqueles que, a exemplo de Ernest Mandel, buscaram alguma síntese, teriam fracassado, pois a síntese foi tentada embasando-se em concepções não dialéticas e, sobretudo, sem compreender o modo de exposição dialético de O Capital. No fundo, esses autores estavam mais preocupados em conhecer os encadeamentos empíricofactuais da crise do que desvendar seu encadeamento conceitual.

Não concordamos que uma leitura causal seja a melhor maneira de se analisar o problema da crise capitalista em Marx, porque tal leitura analisa somente a crise em sua dimensão econômica, porque esta leitura é incapaz de unificar conceitualmente a análise econômica da crise com o movimento político da classe trabalhadora durante o processo de formação e erupção da crise. Pensamos que o caminho mais apropriado para uma interpretação do problema da crise em sua dupla dimensão, econômica e política, é o caminho que concebe a crise a partir de uma análise unitária e dialética dos três livros de O Capital. Caminho que unifica ao mesmo tempo a análise econômica da crise com a análise política.

\section{Os planos de elaboração de O Capital}

Roman Rosdolsky (1986), um clássico estudioso dos Grundrisse e da relação deste com O Capital, foi um dos poucos, talvez o único grande clássico marxista que tentou entender Marx e o problema da crise a partir da noção de modo de exposição dialético [die Darstellungsweise formell] e da relação de O Capital com a Ciência da Lógica de Hegel e os Grundrisse do próprio Marx.

Porém, de acordo com Rosdolsky (1986), Marx não possuía uma teoria completa e sistemática sobre a crise do capital. Segundo ele, Marx planejara realizar uma elaboração sistemática sobre a crise apenas 
nos planos projetados para a redação de O Capital no ano de 1857. Planos que Marx jamais completara e que abandonara já em 1866.

De acordo com Rosdolsky, Marx elaborara dois planos distintos para a redação de O Capital, o primeiro em 1857 e o segundo, modificado, em 1866. Entre esses nove anos ocorrera um período de experimentação e busca constante de uma forma expositiva adequada aos complexos temas de O Capital. Ao longo destes nove anos, desenvolve-se, ao mesmo tempo, uma progressiva restrição dos temas inicialmente projetados. Um dos temas que sofre restrição neste intervalo de tempo, segundo Rosdolsky, é exatamente o tema da crise.

Em seu plano original de 1857, Marx planejara editar sua crítica à economia política dividindo-a em seis partes distintas. Este plano, de acordo com Rosdolsky (1986, pp. 38/39), previa a seguinte divisão da obra 5 :

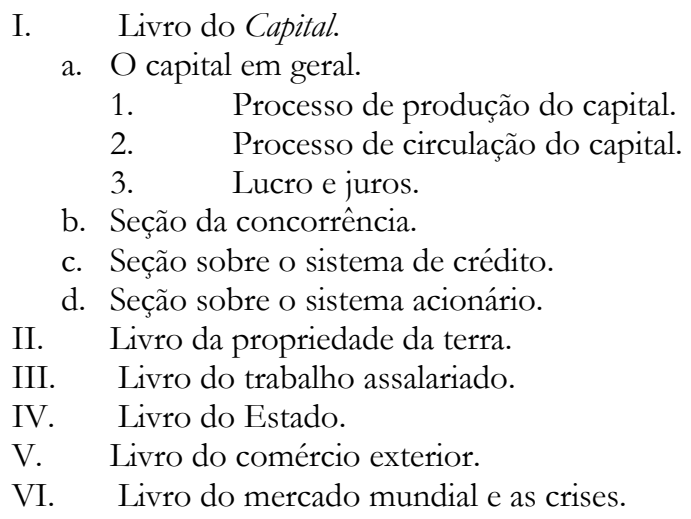

Como podemos perceber, o tema da crise aparece neste esquema de 1857 como o último de todos os temas a ser desenvolvido e, além disso, como tema merecedor de um tratamento especial: o Livro VI, que trataria do mercado mundial e, exatamente, da crise. No intervalo de nove anos de reflexões, contudo, Marx modifica em 1866 este plano original e o substitui por uma divisão tripartite onde o tema da crise aparentemente desaparece.

Esta divisão é a seguinte:

Livro I. Processo de produção do capital.

Livro II. Processo de circulação do capital.

Livro III. Síntese do processo global.

Esta última versão tripartite de 1866 é a forma definitiva de exposição de $O$ Capital concebida por Marx. Como podemos observar, nesta forma definitiva foi suprimido não apenas o Livro VI sobre o mercado mundial e a crise, mas ainda os Livros II, III IV e V sobre o Estado, sobre o comércio exterior, sobre o trabalho assalariado e sobre a propriedade da terra, projetados em 1857 como temas e livros independentes.

Todos os temas do Livro I de 1857 foram, de uma forma ou de outra, absorvidos dentro da estrutura definitiva encontrada por Marx em 1866, assim como os temas dos Livros II e III. Os temas sobre a propriedade da terra (Livro II) e sobre o trabalho assalariado (Livro III) foram tratados, mesmo que tenham deixado de possuir livros específicos em 1866, nos Livros I e III definitivos. Foram suprimidos, 
porém, também os Livros IV, V e VI de 1857, sem que os temas ali projetados aparecessem claramente desenvolvidos dentro da estrutura de 1866.

Rosdolsky argumenta que a redação desses três últimos livros de 1857 (Livro IV - Estado; Livro V - comércio exterior; e Livro VI - mercado mundial e crise) nunca foi totalmente abandonada por Marx porque o plano de redação desses livros foi sendo abandonado entre os anos de 1857 e 1866, sendo reservado para um eventual prosseguimento futuro da obra, prosseguimento que nunca ocorreu segundo Rosdolsky.

Assim, para Rosdolsky, a dificuldade de encontrarmos uma exposição sistemática sobre a crise em Marx decorreria exatamente da ausência desta teoria no próprio O Capital, ausência que teria dado origem a uma lacuna no conjunto da obra. O que Rosdolsky não compreende é que o que está em jogo nos planos de exposição não é a crise em suas manifestações empíricas e ordinárias, mas, sim o conceito de crise.

Apesar de Rosdolsky avançar em alguns pontos na compreensão do problema da forma de exposição de $O$ Capital (reflexão ausente na ampla maioria dos estudiosos da obra e do tema da crise), Rosdolsky não avançou, contudo, da mesma maneira, na compreensão do tema da crise para além do ponto da compreensão não dialética dos autores já citados.

Nós pensamos, ao contrário de Rosdolsky e de toda a bibliografia sobre o tema, que a aparente ausência de uma teoria sistemática sobre a crise do capital deve-se à falta de compreensão do caráter dialético da exposição em O Capital.

\section{A exposição dialética da crise do capital}

Marx não produziu uma teoria, uma demonstração ou uma exposição da crise do capital em suas manifestações empíricas e habituais. Marx produziu, sim, uma exposição do conceito de crise enquanto tal, da crise sem consideração por seus encadeamentos empíricos e factuais. Mas esta concepção, contudo, não foi compreendida desta maneira por Rosdolsky e a tradição marxista já citada.

Marx possuía e realizou, sim, uma exposição completa e sistemática da crise do capital. Contudo, esta teoria não está depositada empiricamente, aqui ou ali, em nenhum texto específico ou passagem canônica de $O$ Capital nem numa soma aritmética de passagens. Esta teoria está, sim, desenvolvida em todo o percurso dialético-expositivo de $O$ Capital, aparecendo e começando a se desenvolver logo nas primeiras páginas do Livro I e se encerrando nas últimas páginas do Livro III. De um livro a parte e separado dos outros livros em 1857, o tema da crise passou a ser um tema imanente a todos os livros concebidos na estrutura definitiva de 1866.

Somente tomando a noção dialética de exposição como pressuposto, consideramos que se possa atingir uma correta compreensão sistematizada do tema da crise. Tema que envolve todas as categorias de O Capital, desde a circulação simples, a produção da mais-valia, a acumulação originária, a reprodução anual do capital social e a realização global da mais-valia até atingir finalmente a noção plena de crise como e enquanto resultado $0^{6}$ no Livro III. 
Como o próprio Rosdolsky em parte indica, nos anos que vão de 1857 a 1866, Marx percebe que suas análises não poderiam ser expostas sem uma determinada forma rigorosa. Marx foi percebendo, cada vez mais, que o conteúdo era inseparável de uma certa forma ou lexis específica.

Assim, nesse período, Marx foi re-construindo e re-ordenando o conteúdo analítico de suas pesquisas em uma forma superior. Neste intervalo de nove anos, através do método expositivo da dialética, o único capaz de dar conta da complexa estrutura categorial do capital, Marx superou o conteúdo analítico das suas descobertas, chegando a uma forma ao mesmo tempo analítica e sintética, ou seja, à forma da dialética superior.

Em 1866, Marx estabeleceu, então, de forma mais clara todo o seu conteúdo analítico, superou as formas empíricas de suas investigações e elevou-as ao caminho da exposição dialética. Caminho que deve partir da totalidade tomada como um concreto indeterminado, como um concreto pressuposto. A partir deste momento, a exposição deve caminhar pelo abstrato, expondo detalhadamente as diversas formas particulares da totalidade, chegando, enfim, ao terceiro momento, onde pouco a pouco ocorre a superação destas formas abstratas que devem retornar ao concreto reconstruído, então, como concreto determinado, como totalidade concreta ou universal concreto.

Este seria o método que daria "vida à matéria" [Leben des Stoffs], como afirma Marx no Posfácio da Segunda Edição de O Capital (Karl Marx, 1962, p. 27). Ou seja, este seria o método que reconstrói o concreto histórico na teoria a partir de suas determinações mais simples e abstratas conduzindo-o ao movimento contraditório que transforma a teoria em vida e em práxis revolucionária. Por isso, pensamos que para Marx o conceito de crise é inseparável do próprio conceito de capital e que o estudo de um implica necessariamente no estudo do outro.

\section{Quatro aspectos dialéticos e formais do Capital}

Uma análise dialética do conceito de crise deve se desenvolver, portanto, simultaneamente com a análise e desenvolvimento do conceito de capital. A obra O Capital, como sabemos, tem como meta expor o conceito de capital, o fundamento, o Grund e a arkhé, da sociedade burguesa. Assim, no trajeto expositivo dos três livros de $O$ Capital, ressaltamos quatro questões fundamentais para a compreensão de nosso trabalho.

1) Primeiro aspecto: os Livros I e II possuem como objeto o conceito mais genérico e mais abstrato de certos momentos do movimento do capital. Nestes livros, vemos o movimento do conceito de capital em suas formas mais puras e abstratas, o conceito de capital enquanto tal, sem consideração por suas formas particulares como o capital comercial e a juros.

Os Livros I e II não possuem como objeto, portanto, as leis e contradições do capital em sua atualidade, em sua enérgeia, mas as leis e contradições do capital somente ainda em sua forma potencial, em sua dynamis. O capital e a sociedade capitalista em sua configuração mais real e concreta são analisados somente no Livro III. Será, portanto, somente neste Livro III que a sociedade capitalista será concebida com todas as suas determinações, sobretudo, com aquelas determinações provocadas pela pluralidade de 
capitais, pela concorrência e pela partilha da mais-valia global entre os diversos capitalistas e ramos individuais da produção.

Os Livros I e II são livros mais abstratos exatamente porque neles colocam-se entre parênteses, em grande parte, a pluralidade de capitais, a concorrência e a partilha da mais-valia. A luta entre os diversos capitais individuais que se odeiam reciprocamente não aparece de forma mais desenvolvida antes do Livro III, apesar de já ser mencionada mesmo no Livro I. Porém, postas a pluralidade de capitais e a concorrência de forma desenvolvida no Livro III, a exposição sobre o conceito de capital passa, então, a possuir todas as determinações na sua forma plena e integral.

2) Segunda questão que gostaríamos de ressaltar: nos Livros I e II analisa-se, particularmente, o conceito de crise também de modo mais puro e abstrato. As muitas contradições que remetem ao conceito de crise, que já aparecem nesses livros, mostram-se como contradições ainda bastante formais, potenciais e abstratas. Nesses livros, no Livro I especialmente, Marx (1962, p. 128) fala apenas da possibilidade da crise [Möglichkeit der Krisen] e não ainda da sua realidade [Wirklichkeit]. Nas Teorias sobre a Mais-valia (Karl Marx, 1972, p. 510), Marx fala da possibilidade geral e abstrata da crise [Allgemeine, abstrakte Möglichkeit der Krise], da crise potencial [Krise potentia] e da forma mais abstraita da crise [abstrakteste Form der Krise].

A crise se converte em realidade plena somente no Livro, III porque somente ali serão postas de forma desenvolvida a pluralidade de capitais e a concorrência. No Livro III seriam postas ainda, de forma plenamente desenvolvida, também as classes sociais em luta, objeto do capítulo LII, do qual, como sabemos, só temos algumas linhas.

De acordo com Marx (1973, p. 33), no Livro III a exposição passa da análise das formas abstratas do capital e da crise à exposição das formas concretas [konkreten Formen] e ao movimento do capital considerado como um todo [Bewegungsprozeß des Kapitals, als Ganzes betracht], ao seu movimento real [wirklichen Bewegung].

3) Terceiro aspecto: nos dois primeiros livros a pluralidade de capitais e a concorrência foram abstraídas da exposição exatamente porque elas não fundam as leis e tendências gerais da sociedade capitalista. O papel da pluralidade de capitais e da concorrência na exposição dialética de Marx é o de transformar em realidade e em coisa concreta as contradições meramente potencias dos Livros I e II que ainda existiam abstratamente, como coisas abstratas e indeterminadas 7.

4) Quarto aspecto: no Livro I são analisadas de modo formal e abstrato as leis da produção da mais-valia enquanto tal, da mais-valia em seu nível mais puro e idealizado. No Livro II são analisadas, do mesmo modo formal e abstrato, as condições puras e idealizadas para a realização da mais-valia global, ainda que esta já esteja posta mais abstratamente desde o início pelo Livro I. No Livro III, finalmente, analisa-se a repartição desta mais-valia global já produzida [Livro I] e realizada [Livro II] entre a pluralidade dos capitais individuais.

\section{Os três grandes momentos dialéticos do conceito de crise}


Assim, uma exposição dialética do conceito de capital e de crise deve ser dividida em três grandes momentos. O primeiro momento abrange a exposição das contradições mais genéricas e potenciais contidas na esfera da produção no Livro I, onde se realiza uma primeira totalização, ainda parcial e abstrata, da produção capitalista, desde suas formas mais elementares, como a mercadoria e o dinheiro, analisados na Primeira Seção, até a sua destruição e crise final, a negação da negação e a expropriação dos expropriadores, exposta no Capítulo XXIV sobre a acumulação primitiva.

No segundo momento, aquele do Livro II, se realiza a exposição das contradições abstratas e potenciais contidas na esfera da circulação, porém, já com as determinações obtidas no Livro I. Por isso, no Livro II parte-se não mais da forma mercadoria em geral, como no Livro I, mas se parte sim, da mercadoria como produto do capital e supondo já a mais-valia (M’). Porém todo o processo contraditório se desenvolve ainda com a abstração da pluralidade de capitais, da concorrência e da partilha da mais-valia. A crise aparece por isso, nesta etapa, ainda apenas em suas formas potencias e abstratas.

Finalmente, no terceiro grande momento, aquele formado pelo Livro III, produção e circulação (Livros I e II) são unificadas e se analisa a conversão em realidade de todas as contradições potenciais e abstratas descritas anteriormente, contradições submetidas agora à existência da pluralidade de capitais e da concorrência. O Livro III, por isso, como sabemos, tem exatamente como subtítulo "O processo total da produção capitalista" [Der Gesamtprozess der kapitalistischen Produktion]. Nele, trata-se da síntese dos resultados obtidos nos dois primeiros livros agora transformados pelas determinações da concorrência entre os múltiplos capitais e onde a crise torna-se finalmente realidade.

\section{Da luta abstrata e parcial à luta concreta e total contra o capital}

Consequentemente, este caminho de ascensão do abstrato ao concreto unifica dialeticamente dois importantes movimentos conceituais e lógicos da exposição crítica de Marx.

1) Primeiro movimento: a análise da possibilidade geral e abstrata da crise. Movimento que pode ser dividido em duas partes.

Primeira parte: a circulação formal entre mercadoria e dinheiro, a compra e venda da força de trabalho e seu consumo na esfera da produção e a reprodução global do capital social. Esta parte é analisada no Primeiro Livro do Capital.

Segunda parte: os ciclos do capital e a circulação capitalista da mercadoria e do dinheiro, a rotação global do capital, a reprodução e a circulação do capital social total. Esta parte está analisada no Segundo Livro do Capital.

Este primeiro momento apresenta o processo de formação da crise a partir de suas muitas possibilidades gerais e abstrata. Este movimento apresenta, ao mesmo tempo, as diversas lutas isoladas e parciais entre capital e trabalho, especialmente em torno do salário, da duração e da intensidade da jornada de trabalho, que têm lugar neste processo.

2) Segundo movimento: a conversão em realidade da possibilidade geral da crise. Este momento é analisado no Livro III do Capital, onde são expostos os capitais individuais e a concorrência capitalista. 
Este último momento apresenta a luta capitalista em torno da partilha da mais-valia, a queda tendencial da taxa de lucro e a eclosão da crise como uma coisa real e concreta no universo do mercado mundial. Este momento transforma, então, em realidade a crise geral do sistema, seu colapso, seu afundamento geral e total, e permite, assim, revolucionar o capitalismo através da luta de classes, que agora se desenvolve no palco do mercado mundial e não mais isoladamente como no Livro I, especialmente.

Assim, este movimento contido ao longo da exposição dos três livros do Capital, transforma em realidade tudo aquilo que existia ainda como mera possibilidade nos Livros I e II. Este longo e árduo movimento, lógico e real, transforma em realidade não somente todas as possibilidades gerais de crise, mas transforma, igualmente, em realidade todas as diferentes formas e possibilidades políticas de luta revolucionária entre capital e trabalho.

É este duplo movimento, econômico e político, contido simultaneamente nos três livros de $O$ Capital que nós devemos compreender para transformá-lo em uma obra não somente de crítica, mas, sobretudo, de crítica da crítica e revolucionário. Esta compreensão dialética é a única compreensão capaz de conduzir as lutas sindicais, parciais e abstratas, do movimento operário em torno de questões como o salário e a duração da jornada de trabalho, na direção de uma luta concreta e política contra a totalidade do sistema capitalista.

\section{Conclusão}

Partindo-se de categorias abstratas tais como valor de uso e valor, valor-de-troca e valor, substância e forma do valor, trabalho abstrato e trabalho concreto, mercadoria e dinheiro, produção de mais-valia, acumulação de capital, acumulação originária, reprodução do capital, realização global do capital anual e assim por diante, chega-se até as determinações reais e concretas do capital, tais como a forma lucro, a taxa de lucro e a queda tendencial da taxa de lucro expostas no Livro III.

Procuramos, assim, sustentar que o processo de desenvolvimento da crise, o processo de conversão de sua possibilidade formal e abstrata em realidade, é o mesmo processo que concretiza todas as contradições mais simples e abstratas do capital, mostrando essas contradições, finalmente, como luta de classes, expropriação dos expropriadores, negação da negação e superação do modo de produção capitalista: último e derradeiro desenvolvimento da teoria marxista da crise.

Somente partindo dessa concepção dialética de exposição podemos desvelar, então, como se desenvolve, de forma mais detalhada, o conceito de crise ao longo dos três livros de O Capital. Conceito que segundo Marx desembocaria no colapso e na derrocada inevitável, mais cedo ou mais tarde, do sistema capitalista como um todo. Derrocada provocada pelas contradições imanentes e fundamentais do capital: as contradições das classes em luta.

Somente assim, lendo O Capital não somente como obra de crítica das categorias econômicas da velha Economia Política, mas, sobretudo, como uma obra dialética e de crítica política e revolucionária do sistema capitalista como um todo, poderemos encontrar uma visão unificada de Marx sobre o capitalismo 
e suas tendências políticas futuras, sem a necessidade de lhe corrigir ou de lhe completar com análises empiristas e factuais da realidade que nada acrescentam à grandiosidade de seu talento e de sua obra teórica.

\section{Referências}

BENOIT, Hector. Sobre a crítica (dialética) de O capital. In. Revista Crítica Marxista número 03. São Paulo: Editora Brasiliense, 1996.

BENOIT, Hector \& ANTUNES, Jadir. O Problema da Crise Capitalista em O Capital de Marx. Jundiaí SP: Editora Paco, 2016.

COLLETTI, Lucio (ed.). Il marxismo e il "crollo" del capitalismo, Bari: Laterza, 1977.

GROSSMANN, Henryk. The Law of Accumulation and Breakdown of the Capitalist System. London: Pluto Press, 1992.

HILFERDING, Rudolf. Le capital financier : étude sur le développement récent du capitalisme. Paris: Éditions de Minuit, 1970

LUXEMBURG, Rosa. Oeuvres III: L'accumulation du capital (I). Contribution à l'explication économique de l'impérialisme. Paris: François Maspero, 1969.

MANDEL, Ernest. La crise: les faits, leur interprétation marxiste. Paris: Flammarion, 1994.

MARX-ENGELS WERKE (MEW). Band 23. Berlin: Dietz Verlag, 1962.

MARX-ENGELS WERKE (MEW). Band 25. Berlin: Dietz Verlag, 1973.

MARX-ENGELS WERKE (MEW). Band 26.2. Berlin: Dietz Verlag, 1972.

MARX, Karl. O capital. Livro Primeiro - Volume II. São Paulo: Nova Cultural, 1988.

ROSDOLSKY, Roman. Génesis y estructura de El capital de Marx: estudios sobre los Grundrisse. Siglo Veintiuno Editores: México, 1986.

SWEEZY, Paul M. The Theory of Capitalist Development: Principles of Marxist Political

Economy. Delhi: Aakar Books, 2016

\section{Notas:}

1 Doutor e Pós-doutor em Filosofia pela Unicamp SP e Professor do PPG de Filosofia da Unioeste PR. ORCID: https://orcid.org/0000-0002-6985-7139 Email: jadir.antunes@yahoo.com.br

2 Veja-se Hector Benoit \& Jadir Antunes. O Problema da Crise Capitalista em O Capital de Marx. Jundiaí SP: Editora Paco, 2016.

3 Veja-se: Rosa Luxemburg. Oeuvres III: L'accumulation du capital (I). Contribution à l'explication économique de l'impérialisme. Paris: François Maspero, 1969. Apresentação de Irène Petit e tradução de Marcel Ollivier e Irène Petit; Henryk Grossmann. The Law of Accumulation and Breakdown of the Capitalist System. London: Pluto Press, 1992; Rudolf Hilferding. Le capital financier : étude sur le développement récent du capitalism. Paris: Éditions de Minuit, 1970. Tradução de Marcel Ollivier; Paul M. Sweezy. The Theory of Capitalist Development: Principles of Marxist Political Economy. Delhi: Aakar Books, 2016; Ernest Mandel. La crise: les faits, leur interprétation marxiste. Paris: Flammarion, 1994.

${ }_{4}^{4}$ Coleção clássica de textos que debatem o problema da crise capitalista no começo do século XX entre intelectuais marxistas se encontra em Lucio Colletti (ed.). Il marxismo e il "crollo" del capitalismo. Bari: Laterza, 1977.

5 Sobre os planos de elaboração de O Capital de acordo com Rosdolsky, a elaboração original e as posteriores modificações, vejase o Capítulo 2 da Primeira Parte Introdutória de Génesis y estructura, chamada La estructura de la obra de Marx, pp. 37 a 100 principalmente.

${ }^{6}$ Sobre o modo de exposição dialético de O Capital veja-se Hector Benoit. Sobre a crítica (dialética) de O capital. Revista Crítica Marxista, número 03. São Paulo: Editora Brasiliense, 1996.

7 A concorrência, para Marx, é sempre fonte de perturbação e engano para o pensamento e, por isso, para apreendermos o conceito de capital em sua imanência é necessário sua abstração. "Na concorrência [diz Marx] aparece, pois, tudo invertido [es erscheint 
also in der Konkurrenz alles verkehrt]. A figura acabada [fertige Gestalt] das relações econômicas, tal como se mostra na superfície, em sua existência real e, portanto, também nas concepções mediante as quais os portadores e os agentes dessas relações procuram se esclarecer sobre as mesmas, difere consideravelmente, sendo de fato o inverso [verkehrt], o oposto [gegensätzlich], de sua figura medular [Kerngestalt] interna, essencial mas oculta [wesentlichen aber verhüllten], e do conceito [Begriff] que lhe corresponde”. O capital. Livro Primeiro - Volume II. São Paulo: Nova Cultural, 1988, p. 153. MEW 23 - 1962, p. 219. 